\title{
Antibiotic Resistance: What is there in Past, Present and Future?
}

\author{
Raman Palanisamy Priyadharsini* \\ Department of Pharmacology, Jawaharlal Institute of Postgraduate Medical Education and Research (JIPMER), Karaikal, Puducherry, INDIA.
}

\begin{abstract}
The burden of the resistance to the antibiotics increases day by day and there is a high chance that even minor infections can kill patients in future. There is a high resistance to third generation cephalosporins and fluoroquinolones among Acinietobacter baumanni, Escherchia coli, Klebsiella pneumonia and Pseudomonas aeruginosa. The carbapenam resistance is also increasing among these bacteria. The colistin is the drug used in the treatment of carbapenam resistance and the colistin resistance also has increased. CDSCO has restricted the use of higher antibiotics carbapenams class III and IV for resistant infections. The factors influencing antibiotic resistance are many and WHO has recommended strategies to decrease the mortality and morbidity of antibiotic resistance.
\end{abstract}

Key words: Antibiotics, Resistance, Post-antibiotic era, Irrational, Selfmedication.

\section{Correspondence}

Dr. Raman Palanisamy Priyadharsini,

Department of Pharmacology, JIPMER, III Cross, Nehru Nagar, Karaikal-609602, Puducherry, INDIA.

Phone: +91 8870832242

Email: drpriya.rp@gmail.com

DOI: 10.5530/jyp.2019.11.69

\section{INTRODUCTION}

Antibiotic resistance is a global health problem of serious concern. The estimated deaths due to antimicrobial resistance globally is 7,00,000 per year and the number of deaths would increase to 10 million by the year 2050. ${ }^{1}$ The major reasons for antibiotic resistance include irrational prescribing behavior, inappropriate prescription of antibiotics, use of antibiotics as growth promoters, less availability of newer antibiotics and for the treatment of infection in animal husbandry. ${ }^{2,3}$ The first discovery of antibiotics was accidental which saved millions of lives but the emerging antibiotic resistance due to irrational use of antibiotics can lead to post antibiotic era, in which minor infections will kill patients. ${ }^{4}$ India was the third highest in consuming antibiotics next to USA and China and the crude infectious disease mortality is about 416.75 per 10,000 persons. $^{5}$ There is an increasing demand for the vigilance of the antibiotic prescribing pattern.

\section{Timeline of antibiotic resistance}

The first discovery of antibiotic by Alexander Fleming is in 1920s and the pencillinase enzyme was identified in 1940. In 1930s the sulfonamides were discovered which developed resistance subsequently. The streptomycin was discovered in 1944 for the treatment of TB and the resistance to the drug was identified during the patient treatment itself. The drug methicillin was discovered in 1961 targeting pencillinase producing organisms which also failed as a antibiotic with the development of methicillin resistant staph aureues. Vancomycin was discovered in 1972 and the resistant strains of vancomycin developed in 2002. Ampicillin was introduced for the treatment of infections due to Enterobacteriaceae and after a short period ampicillin resistant strains were identified in $1962 .^{6-8}$

\section{Factors leading to antibiotic resistance}

The reasons are the increased usage of broad spectrum antibiotics, irrational use of antibiotics, self-medication, increased consumption of antibiotic FDCs, increased antibiotic usage in animals, lack of access to sanitation facilities, pollution of the rivers by pharmaceutical companies, presence of antibiotic resistance bacteria in poultry, livestock, social and cultural factors ${ }^{9,10}$

\section{Irrational use}

Some clinical conditions do not require antibiotics like tooth ache, acute viral pharyngitis acute bronchitis, mild to moderate pancreatitis, asymptomatic bacteriuria in women. In India it was estimated that around $50 \%$ of antibiotic use in the health care systems was inappropriate and in order to prevent the irrational use national center for disease control issued a publication called national treatment guidelines to promote rational use. ${ }^{11,12}$ A study conducted in France showed that out of 122 antibiotic treatments it was found that $34 \%$ of treatments are misdiagnosed and 30\% treatments are not used appropriately. ${ }^{13}$ There is need to set proper guidelines and antibiotic policies towards the rational prescription of drugs

\section{Self-medication}

The reason attributed to the high degree of self-medication in developing countries is due to is the cost expenses in approaching the health care and the availability of the over the counter medications. ${ }^{14}$ A study conducted among the non-medical students in three universities found that $58.3 \%$ of the 727 students took self-medication in the past six months and metronidazole was the most common drug misused ${ }^{15}$

\section{Antibiotic resistance in poultry, animal husbandry and fishing}

India will be the fourth largest consumer of antibiotics in food animals by $2030 .{ }^{10}$ A study conducted in Korea evaluated the presence of antibiotic resistant bacteria in chicken meats which found that $51 \mathrm{E}$. coli isolates were identified in 51 chicken meats and they were resistant to ampicillin(75\%), tetracycline(69\%), ciprofloxacin, trimethoprim/ sulfmethaxozole, ceftiofur, amoxicillin/clavulanic acid ${ }^{16}$

The trend of using antibiotics as growth promoters in animals started in $1950 \mathrm{~s}$ when the drugs procaine penicillin and tetracycline was used 
in animals like pigs and cows. The use of the antibiotics in fish food contaminates the water ponds leading to transmission of resistance among the exposed organisms. Another mode of transmission of antibiotic resistant bacteria in veterinarians, slaughterhouse people and farmers is through close contact with animals ${ }^{17}$ The measures should be considered to restrict the use of antibiotics in poultry and agriculture to prevent antibiotic resistance.

The mechanisms of the antibiotic resistance are the mutational resistance of the gene on which the drug acts, horizontal gene transfer of the resistant gene, decreased influx and increased efflux of the drug, drug destroying mechanisms by the enzymes produced by the bacteria ${ }^{18}$

\section{EMERGING TRENDS IN ANTIMICROBIAL RESISTANCE}

The drug susceptibility testing metaanalysis in India showed that there is high resistance among the organisms Staphylococcus aureus, Klebsiella pneumonia, Salmonella, Shigella, Vibrio cholerae, Neisseria gonorrhoeae, N. meningitidis, Mycobacterium tuberculosis ${ }^{19}$

A study conducted retrospectively to study the trends in antibiotic resistance between periods 2008 to 2014 reported that the main reason of bacteremia in children is caused by enteric fever and more than $95 \%$ of the salmonella typhi and paratyphi are resistant to nalidixic acid. The vancomycin resistance in Enterococcus faecalis is $17 \%$. The carbapenam resistance for Klebsiella pneumonia (56.6\%) E. coli (11.5\%) Acinetobacter (69.6\%) and Pseudomonas aeruginosa (49\%) The main mode of treatment for the carbapenam resistance is colistin and colistin resistance is also increased The bacteria Acinietobacter baumanni, Escherchia coli, Klebsiella pneumonia and Pseudomonas aeruginosa showed high resistance to third generation cephalosporins and fluoroquinolones. ${ }^{20}$ There is a high prevalence of beta lactamases an metallobetalactamases production from the isolates of $P$. aeruginosa and A. baumanni in different samples. ${ }^{21}$

Kaur et al. 2017 reported that the mortality rate of the blood stream infection due to colistin resistance in Klebsiella pneumoniae is $69.3 \%$ in a group of Indian patients. ${ }^{22}$ A prospective study conducted in the intensive care units of Delhi reported that the neonatal sepsis caused by Acinetobacter baumanii and Klebsiella pneumonia and the bacterial strains were multi drug resistant. ${ }^{23}$

A recent study indicates that Mfd is an evolution factor which mediates mutagenesis in bacteria and causes antimicrobial resistance. The discovery of antievolution drugs which targets the Mfd can be a potential target to reduce the resistance ${ }^{24,25}$ history shows that resistance arises regardless of the nature or potency of new drugs. Here, we propose and provide evidence for an alternate strategy to resolve this problem: inhibiting evolution. We determined that the DNA translocase Mfd is an "evolvability factor" that promotes mutagenesis and is required for rapid resistance development to all antibiotics tested across highly divergent bacterial species. Importantly, hypermutator alleles that accelerate AMR development did not arise without Mfd, at least during evolution of trimethoprim resistance. We also show that Mfd's role in AMR development depends on its interactions with the RNA polymerase subunit RpoB and the nucleotide excision repair protein UvrA. Our findings suggest that AMR development can be inhibited through inactivation of evolvability factors (potentially with "anti-evolution" drugs

\section{ECONOMIC BURDEN OF ANTIMICROBIAL RESISTANCE}

The economic burden of the antimicrobial resistance is calculated by the amount spent in treating the cases due to antimicrobial resistance when compared with the sensitive cases. The direct costs is the money spent directly in treating the resistant infections and indirect cost is the cost that society bears due to the early deaths out of the drug resistance. A study calculated the direct and indirect cost due to AMR in USA and Thailand. In US it was estimated that among 14 million bacterial infections 1.2 million infections were due to AMR and the direct cost per infection was 1415 US dollars. The total cost of antimicrobial resistance in selected five pathogens is 2.8 billion dollars in United states and 0.5 billion dollars in Thailand. ${ }^{26}$

In India it was estimated that around 5\% of GDP was spent on health system out with which public sector contributing $0.9 \%$ and the remaining by private sector ${ }^{19}$

Drug resistant index is the economic index which directly measures the consumer prices and stock market value for the drug. Any change in DRI per year will identify the decreased efficacy of antibiotic. The effectiveness of antibiotic policy implemented can be also identified by drug resistance index..$^{27}$

\section{ANTIMICROBIAL RESISTANCE IN INDIA}

The current status is that research and funding on the antimicrobials development is less. The areas of research on antimicrobial resistance focused mainly on the epidemiology, mechanisms of resistance, intervention studies, policy related and reviews but the national wide surveillance is $\operatorname{low}^{28}$ India being the largest consumer utilized about $12.9 \times 10^{9}$ units of antibiotics for human health in the year 2010. The use of ampicillin, cotrimoxazole is decreasing whereas the carbapenams, colistin usage is on the rise. ${ }^{5}$ In India the methicillin resistant staph aureus strains have increased from $29 \%$ to $47 \%$ in 2015 . There is also an increase in the resistance of the carbapenam reistant $E$. coli and Klebsiella pneumoniae isolates. ${ }^{29}$

\section{STEPS TAKEN BY CDSCO}

The sales of carbapenams in Egypt, India and Pakistan is on the rise with the standard units of 1.2 per 1000 population in $2010 .{ }^{30}$ Coordinated action is largely absent, especially at the political level, both nationally and internationally. Antibiotics paved the way for unprecedented medical and societal developments, and are today indispensible in all health systems. Achievements in modern medicine, such as major surgery, organ transplantation, treatment of preterm babies, and cancer chemotherapy, which we today take for granted, would not be possible without access to effective treatment for bacterial infections. Within just a few years, we might be faced with dire setbacks, medically, socially, and economically, unless real and unprecedented global coordinated actions are immediately taken. Here, we describe the global situation of antibiotic resistance, its major causes and consequences, and identify key areas in which action is urgently needed."' DOI":"10.1016/S1473-3099 (13 CDSCO has put forward the steps to reduce the burden of antimicrobial resistance in India. A schedule $\mathrm{H} 1$ was released for the restricted use of carbapenam, class III and IV and anti TB drugs only for resistant infections. The Drugs and cosmetics rules demand the mentioning of withdrawal period on the label of the drugs used in animals so that the drug levels are not exceeded in food producing animals. The Ministry of agriculture had advised the veterinary doctors to use the antibiotics appropriately in the treatment of animals. The members of Indian medical association were advised to follow the standard treatment of guidelines while treating infections in patients. ${ }^{31}$

ICMR has restricted the use of carbapenams and polymyxins labeling them as end use antibiotics. It was noted that $5-7 \%$ of the patients working in intensive care unit are resistant to such antibiotics. 


\section{GLOBAL PROGRESS ON TACKLING ANTIMICROBIAL RESISTANCE STEPS TAKEN BY WHO}

The misuse and overuse of antibiotics has led to the increased resistance of infections like tuberculosis, pneumonia, gastro enteral infections and urinary tract infections. This will lead to the emergence of post antibiotic era in which the mortality can increase due to minor infections. WHO has addressed various groups like health professionals, individuals, policy makers, health care sector and agricultural industry with various measures to resolve the magnitude of the problem. ${ }^{4}$

WHO demands the various countries to find approaches to tackle antibiotic resistance? As per the report released by FAO and WHO there exists a surveillance system in 105 countries, tracking system for the consumption of antibiotics in 68 countries and policies in 123 countries to monitor the sales of the antimicrobials.

The various measures taken by WHO include 2001-Global strategy for the containment of antimicrobial ressiatnce 2012- Evlolving threat of antibiotic resistance 2014- first global report on antibiotic surveillance ${ }^{32}$

\section{The Global antimicrobial resistance surveillance system (GLASS)}

The surveillance system was started in October 2015 with the aim of strengthening the evidence on the data on antimicrobial resistance. The main objectives of GLASS include collecting, analyzing and reporting the data so as to make decisions at global level to reduce the impact of antimicrobial resistance. It was planned during the period 2015-2019. ${ }^{33}$

\section{Global Antibiotic Research and Development Partnership (GARDP)}

GARDP is initiated by WHO and DNDi (Drugs for neglected diseases initiative) to promote the research and development of newer antibiotic treatments by working with public and private sectors. It was launched in May 2016 with a seven year plan $^{34}$ The key approaches of GARDP include partnership with health authorities, pharmaceutical industries, research organizations and promote antibiotic research globally. The programmes mainly focus on the research on the drugs used for the treatment of drug resistance in management of sexually transmitted diseases, neonatal sepsis and paediatric infections. ${ }^{35}$

\section{Interagency Coordination Group on Antimicrobial Resistance (IACG)}

It was a coordination group formed in September 2016 after consulting WHO, FAO and World Organization for animal health. The objective is to combat antibiotic resistance by providing practical guidance and to implement a global plan. ${ }^{36}$

\section{CONCLUSION}

The treatment of infections solely depend on antibiotics and there are raising concerns on superbugs a micro-organism that has developed resistance to the most commonly used antibiotics. CDSCO has also taken various steps to have a check over the use of antibiotics. Despite the strategies and the initiative taken by WHO in the global progress the impact of antibiotic résistance on health care is huge. There is a need for change in the antibiotic prescribing practice, rational prescribing, implementation of proper guidelines for every health sector, awareness on self-medication among the public, restriction of use of antibiotics, agriculture, poultry to reverse this trend.

\section{ACKNOWLEDGEMENT}

None.

\section{CONFLICT OF INTEREST}

None.

\section{REFERENCES}

1. First independent framework for assessing pharmaceutical company action Antimicrobial Resistance Benchmark 2018. Netherlands. 2017.

2. Ventola CL. The Antibiotic Resistance Crisis. Pharm Ther. 2015;40(4):277-83.

3. Wojkowska-Mach J, Godman B, Glassman A, Kurdi A, Pilc A, Rozanska A, et al. Antibiotic consumption and antimicrobial resistance in Poland: Findings and implications. Antimicrob Resist Infect Control. 2018;7(1):136.

4. World Health Oraganization. Antibiotic resistance. 2018. [cited 2018 Apr 26]; Available from: http://www.who.int/news-room/fact-sheets/detail/antibioticresistance

5. Laxminarayan $R$, Chaudhury RR. Antibiotic Resistance in India: Drivers and Opportunities for Action. PLoS Med. 2016;13(3):1-7.

6. Zaman S, Hussain M, Nye R, et al. A Review on Antibiotic Resistance: Alarm Bells are Ringing. Cureus. 2017;9(6):1-9

7. Davies J, Davies D. Origins and Evolution of Antibiotic Resistance. Microbiol Mol Biol Rev. 2010;74(3):417-33.

8. Antibiotic resistance: An unexpected chronology. Eurek Alert. 2017. [cited 2019 Jan 29];Available from: https://www.eurekalert.org/pub_releases/2017-11/ ip-ar112917.php

9. Kaur A, Bhagat R, Kaur N, Shafiq N, Gautam V, Malhotra S, et al. A study of antibiotic prescription pattern in patients referred to tertiary care center in Northern India. Ther Adv Infect Dis. 2018;5(4):63-8.

10. Scoping Report on Anti-Microbial Resistance in India. Department of Biotechnology. [cited 2018 Nov 19];Available from: http://www.dbtindia.nic.in/scopingreport_anti-microbial-resistance/

11. Thompson W, Rios LE, Fedorowicz Z, Dailey Y, Douglas G. I've got Toothache, I need Antibiotics: a UK Perspective on Rational Antibiotic Prescribing by Dentists. Braz Dent J. 2018;29(4):395-9.

12. National Treatment Guidelines for Antimicrobial Use in Infectious Diseases: India. 2016. [cited 2018 Dec 3]. Available from: http://apps.who.int/medicinedocs/ en/m/abstract/Js23118en/

13. Pulcini C, Cua E, Lieutier F, Landraud L, Dellamonica P, Roger PM. Antibiotic misuse: A prospective clinical audit in a French university hospital. Eur J Clin Microbiol Infect Dis. 2007;26(4):277-80.

14. Rather IA, Kim BC, Bajpai VK, Park YH. Self-medication and antibiotic resistance: Crisis, current challenges and prevention. Saudi J Biol Sci. 2017;24(4):808-12.

15. Gillani AH, Ji W, Hussain W, Imran A, Chang J, Yang C, et al. Antibiotic SelfMedication among Non-Medical University Students in Punjab, Pakistan: A Cross-Sectional Survey. Int J Environ Res Public Health. 2017;14(10):1-9.

16. Lee HJ, Cho SH, Shin D, Kang HS. Prevalence of Antibiotic Residues and Antibiotic Resistance in Isolates of Chicken Meat in Korea. Korean J Food Sci Anim Resour. 2018;38(5):1055-63.

17. Marshall BM, Levy SB. Food Animals and Antimicrobials: Impacts on Human Health. Clin Microbiol Rev. 2011;24(4):718-33.

18. Munita JM, Arias CA. Mechanisms of Antibiotic Resistance. Microbiol Spectr 2016;4(2):1-2.

19. Kumar SG, Adithan C, Harish BN, Sujatha S, Roy G, Malini A. Antimicrobial resistance in India: A review. J Nat Sci Biol Med. 2013;4(2):286-91.

20. Gandra S, Mojica N, Klein EY, Ashok A, Nerurkar V, Kumari M, et al. Trends in antibiotic resistance among major bacterial pathogens isolated from blood cultures tested at a large private laboratory network in India, 2008-2014. Int J Infect Dis. 2016;50:75-82

21. Kaur A, Singh S. Prevalence of Extended Spectrum Betalactamase (ESBL) and Metallobetalactamase (MBL) Producing Pseudomonas aeruginosa and Acinetobacter baumannii Isolated from Various Clinical Samples. J Pathog. 2018;1-7.

22. Kaur A, Gandra S, Gupta P, Mehta Y, Laxminarayan R, Sengupta S. Clinica outcome of dual colistin- and carbapenem-resistant Klebsiella pneumoniae bloodstream infections: A single-center retrospective study of 75 cases in India. Am J Infect Control 2017;45(11):1289-91.

23. Agarwal R, Shankar J. Characterisation and antimicrobial resistance of sepsis pathogens in neonates born in tertiary care centres in Delhi, India: A cohort study. Lancet Glob Health. 2016;4(10):752-60.

24. Ragheb MN, Thomason MK, Hsu C, Nugent P, Gage J, Samadpour AN, et al. Inhibiting the Evolution of Antibiotic Resistance. Mol Cell. 2018. Available from: http://www.sciencedirect.com/science/article/pii/S1097276518308475

25. "Anti-Evolution Drugs" Could Offer New Strategy against Antimicrobia Resistance Crisis: GEN-Genet. Eng Biotechnol News. 2018. [cited 2018 Dec 
19];Available from: https://www.genengnews.com/news/anti-evolution-drugscould-offer-new-strategy-against-antimicrobial-resistance-crisis/

26. Shrestha P, Cooper BS, Coast J, Oppong R, DoThi TN, Phodha T, et al. Enumerating the economic cost of antimicrobial resistance per antibiotic consumed to inform the evaluation of interventions affecting their use. Antimicrob Resist Infect Control. 2018;7(1):98.

27. Wattal C. Development of antibiotic resistance and its audit in our country: How to develop an antibiotic policy. Indian J Med Microbiol 2012;30(4):381-3.

28. Antimicrobial Resistance in South East Asia. Fostering research into antimicrobial resistance in India. The BMJ. 2017;358:j3535. [cited 2018 Oct 4];Available from: https://www.bmj.com/content/358/bmj.j3535

29. Kakkar M, Walia K, Vong S, Chatterjee P, Sharma A. Antibiotic resistance and its containment in India. BMJ. 2017;358:j2687.

30. Laxminarayan R, Duse A, Wattal C, Zaidi AKM, Wertheim HFL, Sumpradit N, et al. Antibiotic resistance-the need for global solutions. Lancet Infect Dis.
2013;13(12):1057-98.

31. Advisory Rational Use of Antibiotics for Limiting Antimicrobial Resistance. CDSCO. 2017

32. Prestinaci F, Pezzotti P, Pantosti A. Antimicrobial resistance: A global multifaceted phenomenon. Pathog Glob Health. 2015;109(7):309-18.

33. GLASS. Global Antimicrobial Resistance Surveillance System (GLASS). WHO 2015. [cited 2018 Sep 14];Available from: http://www.who.int/glass/en/

34. About-GARDP. 2016. [cited 2018 Nov 29];Available from: https://www.gardp. org/about/

35. Piddock LJ, GARDP. The Global Antibiotic Research and Development Partnership (GARDP): A not-for-profit antibiotic development organization. Lancet Infect Dis. 2018

36. WHO. UN Interagency Coordination Group on Antimicrobial Resistance. WHO. 2019. s[cited 2018 Nov 29];Available from: http://www.who.int/antimicrobialresistance/interagency-coordination-group/en/

Article History: Submission Date : 25-07-2019; Revised Date : 30-08-2019; Acceptance Date : 24-09-2019.

Cite this article: Priyadharsini RP. Antibiotic Resistance: What is there in Past, Present and Future?. J Young Pharm. 2019;11(4):333-6. 